Editorial

\title{
Journal of lung, pulmonary and respiratory research. a newly born journal in the medical field
}

\section{Introduction}

The Journal of Lung, pulmonary and Respiratory research is a newly born in the wide world of medical journals. Its birth required a great effort by the publishing organization and its authorized team to declare its citation as a shining star in the sky of specialized medical journals as one that deals mainly with pulmonary and respiratory disorders and research work in the same field.

Feeling the effort done to cite the new journal. One can recognize that a closer cooperative spirit between all authorized members gave the smooth birth of that new journal. This ideal spirit good intentions and great effort will strengthen our abilities to cope with the challenges that face the scientific medical media to achieve better and optimal patients' care in all medical fields especially in pulmonary diseases and researches related to that.

Obviously now we are as doctors and researchers are all on the threshold of a new journal citation. For sure the effort of the publishing organization when complimented with a spirit of collaboration, cooperation and sincere desire of our colleagues in both the medical and research fields. This will give the power and the momentum to start as a giant and continue its way steadily and sure. So the effort and sharing of our colleagues are badly needed no matter where they might be with our interaction integration and personal efforts to share
Volume I Issue 2 - 2014

Mohammad Aleem

Department of Cardio Thoracic Surgery, Cairo University, Egypt

Correspondence: Mohammad Aleem, Department of Cardio Thoracic Surgery, Cairo University, Egypt, Tel 002/0106330 I269, Email cardio_thoracic20II@yahoo.com

Received: August 25, 2014 | Published: August 26, 2014

in and guide the journal team to continue growth in a healthy optimum manner to reach that top which is better health for patients.

\section{Acknowledgements}

None.

\section{Conflict of interest}

The author declares no conflict of interest. 